\title{
Diacronie
}

Studi di Storia Contemporanea

$\mathrm{N}^{\circ} 11,3$ | 2012

La satira fa storia. Eventi, pratiche, linguaggi

\section{La sátira y el humor político durante el Tercer Reich}

Los delitos contra la Volksgemeinschaft

Francisco Miguel De Toro Muñoz

\section{(2) OpenEdition}

\section{Journals}

Edición electrónica

URL: http://journals.openedition.org/diacronie/2655

DOI: 10.4000/diacronie.2655

ISSN: 2038-0925

\section{Editor}

Association culturelle Diacronie

Referencia electrónica

Francisco Miguel De Toro Muñoz, «La sátira y el humor político durante el Tercer Reich », Diacronie [En línea], $N^{\circ} 11,3$ | 2012, documento 5, Puesto en línea el 29 octubre 2012, consultado el 01 mayo 2019. URL : http://journals.openedition.org/diacronie/2655; DOI : 10.4000/diacronie.2655 


\section{Diacronie}

\section{$5 /$}

\section{La sátira y el humor político durante el Tercer Reich \\ Los delitos contra la Volksgemeinschaft}

Francisco Miguel De TORO MUÑOZ*

La crítica de la opinión pública aparece en todos los regímenes políticos, pero lo más importante es su capacidad de respuesta para asumir las críticas y darles una respuesta. Es en este ambiente de control de todas las expresiones posibles del pensamiento que se produce el florecimiento de la sátira política, que se nutre de las reservas de imaginación e ingenio a las que el sistema totalitario niega su forma de expresión. Las opiniones "sediciosas" que se presentaban ante los tribunales estaban relacionadas con el humor anti-nazi que fue considerado, en todas sus manifestaciones, como propaganda de oposición. Pero, para poder tener acceso a los “delincuentes", el régimen debía contar con la colaboración de la sociedad. La sátira adoptaba dos objetivos principales: ridiculizaba al sistema, burlándose de sus normativas e instituciones; y evitaban el miedo al régimen, mediante la ridiculización de los aspectos de la vida diaria.

La pequeña resistencia era, en realidad, grande. Formaba la base de masas para la resistencia heroica, que llevaba a la prisión y al patíbulo ${ }^{1}$.

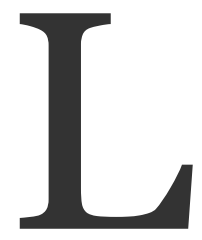

a crítica surgida de la opinión pública aparece en todos los sistemas políticos, sean del tipo que sean, pero en el caso del Nacionalsocialismo lo más importante no fue la aparición de esas críticas, sino la incapacidad del régimen para asumirlas, absorberlas y darles una respuesta más o menos

${ }^{1}$ FREI, Bruno, Der Kleine Widerstand, Wien, Sensen-Verlag, 1978, p. 7. 
efectiva. Algunos historiadores lleguen a la conclusión de que la auténtica "resistencia" es la que se desarrolló dentro de unos grupos de oposición organizados, porque se refiere a comportamientos que rechazan el régimen y buscan su desaparición. Pero la extensión de otro tipo de comportamientos ha llevado a que también podamos encontrar diferentes tipos de conductas que podemos considerar como "oposición" o "disentimiento".

En general, el descontento con el régimen comenzó con los primeros desengaños con las promesas que los dirigentes nazis habían hecho en el momento de su llegada al poder y que no habían cumplido: mejoras salariales, bajada de impuestos, mejoras en las condiciones de vida y de trabajo, etc. Así, los delitos relacionados con la resistencia individual son una buena fuente de información sobre la evaluación del estado de ánimo de la población, igual que el papel creciente que tuvieron en las actividades cotidianas de la policía política nacionalsocialista.

A partir del análisis de los comportamientos que aquí consideramos como delitos contra la Volksgemeinschaft (Comunidad Nacional) nacionalsocialista, podremos proporcionar una imagen de las reacciones de la población a la hora de buscar válvulas de escape al malestar social con las situaciones de excepcionalidad provocadas por el régimen, a las que se enfrentaban en su vida diaria. Esto contrastará con el hecho de que, tras 1933 una parte de la población alemana apoyó al régimen nazi de forma incondicional, mientras que una pequeña minoría se constituyó en el núcleo de la oposición. Pero la gran masa de la población mantuvo un comportamiento ambivalente, en un permanente proceso dinámico que variaba entre el consentimiento y la oposición. Este proceso dinámico estuvo profundamente influido por la situación social y política vivida durante el transcurso del régimen, y variaba según el momento.

Expresiones enemigas del estado, delitos radiofónicos, insultar al Führer, minar la fuerza de defensa del pueblo alemán, expresiones despectivas sobre la Wehrmacht, son algunas de las calificaciones que la policía política y los tribunales utilizaron a la hora de perseguir estas acciones.

\section{El debate historiográfico}

Existen muchos estudios que han resaltado la unidad monolítica del régimen nazi. Pero como se ha demostrado en los últimos años, existieron diferentes tipos de comportamientos, opiniones y actitudes. La sociedad alemana tenía entre sus filas a un 
gran número de descontentos y opositores, y el disgusto sobre cómo iban las cosas podía encontrarse en casi cualquier grupo social.

El análisis de lo que se ha denominado individueller Widerstand (resistencia individual) no puede elaborarse sin tener en cuenta la diversificación de fuentes básicas o sin el análisis de grandes cantidades de documentos. Al mismo tiempo, debemos introducirnos directamente en los preceptos metodológicos de la historia social.

Cuando nos aproximamos a este tema, debemos hacer frente a una serie de dificultades relacionadas, principalmente, con la documentación disponible. En primer lugar, debemos limitarnos únicamente a material procedente de las propias autoridades represivas. El segundo problema es el de la necesidad de utilizar lo que Gerhard Botz denomina “documentos residuales" 2 . Esta documentación nos proporciona un cierto nivel de información sobre el contexto sociocultural en el que se produce ese "comportamiento resistente", pero distinguiendo siempre los actos individuales de las acciones de grupo.

Uno de los primeros historiadores en considerar este tipo de actividades como formas de resistencia fue Martin Broszat, que introdujo el concepto de Resistenz (considerado como oposición) como una serie de actividades destinadas a minar la dictadura totalitaria mediante comportamientos opositores de carácter "informal” y de opiniones disidentes o críticas ${ }^{3}$.

En el marco del proyecto sobre la resistencia en Baviera entre 1933 y 1945 se introdujo la categoría de 'oposición' frente a la de 'resistencia', intentando incluir todas las formas de comportamiento que hacen referencia a una actitud contraria a la ideología nazi4. En el marco de este proyecto se señala que estas formas marginales de oposición individual son relativamente difíciles de concretar, a pesar de que las podemos suponer y confrontar con unos fenómenos más "masivos" y politizados de consenso. La "resistencia individual" marca una frontera entre la hegemonía y la integración del régimen nazi y las zonas de oposición y resistencia entre sectores de la población. Reinhard Mann, por su parte, introdujo el concepto de nonkonformist

\footnotetext{
${ }^{2}$ BOTZ, Gerhard, «Widerstand von einzelnen», in DÖW (Dokumentationsarchiv des österreichischen Widerstandes) (Hrsg.), Widerstand und Verfolgung in Oberösterreich, 19341945: eine Dokumentation, Wien, Österreichischer Bundesverlag, 1982, p. 353. 3 VAN ROON, Ger, Widerstand im Dritten Reich. Ein Überblick, Munich, C.H.Beck Verlag, 1998; UEBERSCHÄR, Gerhard R., Für ein anderes Deutshcland. Der deutsche Widerstand gegen den NS-Staat 1933-1945, Frankfurt, Fischer Verlag, 2006; BENZ, Wolfgang, PEHLE, Walter H. (Hrsg.), Lexikon des deutschen Widerstandes, Frankfurt, Fischer Taschenbuch Verlag, 2008.

4 BROSZAT, Martin, FRÖHLICH, Elke, WIESEMANN, Falk (Hrsg.), Bayern in der NS-Zeit, 4 voll., München, R. Oldenburg Verlag, 1977-1983.
} 
Alltagsverhalten (inconformismo con la vida diaria) 5, que fue posteriormente ampliado por Ian Kershaw y definido como Dissens (disentimiento), definiendo comportamientos, frecuentemente espontáneos, críticos con un aspecto concreto del régimen, pero no con su conjunto, basándose en actos de carácter individual ${ }^{6}$. Hasta hace poco, este tipo de actitudes no fue considerado como un comportamiento de oposición al régimen, y la mayoría de los historiadores no lo han incluido en sus estudios. Pero el estudio de este tipo de delitos nos proporcionará «el espectro total de resistencia, oposición y descontento, de discriminación y represión, también cada reacción inconformista al dominio dictatorial» 7 .

\section{Los delitos contra la Volksgemeinschaft y la sátira política}

Debido al elevado número de personas relacionadas con estos comportamientos, la "resistencia individual" fue una de las formas más extensas de expresión de oposición contra el dominio nazi, hasta el punto que Botz lo denominó kollektive Systemopposition (sistema de oposición colectivo) ${ }^{8}$. Si consideramos que, gracias a la extensión entre la población que tuvieron estos aspectos individuales de resistencia, podemos afirmar que se convirtieron en un sistema colectivo de oposición, comparable a la resistencia política organizada. Rudolf G. Ardelt señaló que estas "colectividades" se diferenciaban de los grupos organizados porque están compuestos, mayoritariamente, por amigos, vecinos, familiares, etc., y no por personas que conformasen una estructura formal, con unos conceptos estratégico-tácticos concretos ${ }^{9}$.

Si el Nacionalsocialismo intentaba transformar y destruir la personalidad individual para crear su Volksgemeinschaft, la resistencia individual se convirtió en un acto de afirmación de la identidad propia de cada "delincuente" y su oposición a la homogeneización nazi. Para comprender mejor la concepción de la "resistencia individual" dentro del marco de un sistema de oposición colectiva, Botz analiza el difícil tema de la "visibilidad" del comportamiento opositor: cada forma de oposición en un sistema dictatorial, desde las demostraciones colectivas abiertas hasta los casos

\footnotetext{
5 MANN, Reinhard, Protest und Kontrolle im Dritten Reich, Frankfurt, Campus Verlag, 1987, p. 30.

6 KERSHAW, Ian, Popular opinion and political dissent in the Third Reich, Bavaria 1933-1945, Oxford, Oxford University Press, 2002; CORNER, Paul (ed.), Popular Opinion in Totalitarian

Regimes. Fascism, Nazism, Communism, Oxford, Oxford University Press, 2009.

7 BOTZ, Gerhard, «Widerstand von einzelnen», cit., p. 353.

8 Ibidem.

9 ARDELT, Rudolf G., «Individueller Widerstand», in DÖW (Hrsg.), Widerstand und

Verfolgung in Salzburg, Wien, Österreichischer Bundesverlag, 1981, pp. 351-363.
} 
aislados e individuales, debe tender a ocultar su verdadera dimensión, para evitar la reacción del régimen. Esto provoca que no sea hasta el momento en que se produce la entrada en acción del aparato de control, que ese comportamiento queda comprendido en la investigación histórica. Es decir, que es la propia intervención del aparato represor la que nos proporciona, en la mayoría de los casos, la evidencia, la "visibilidad" de esa actitud opositora.

Desde el comportamiento "desviado" en los ámbitos privados y la resistencia social desarticulada hasta el comportamiento social opositor y la resistencia política, encontramos una amplia serie de categorías individuales que definen la conducta "inconformista". Muchos aspectos de la "normalidad" de la vida cotidiana fueron súbitamente criminalizados, porque determinados aspectos de la vida diaria no podían criticarse. Las opiniones personales y las noticias difundidas clandestinamente crearon nuevos "medios de transmisión", como los rumores, los versos satíricos, el humor político, etc., que adquirieron un gran significado en la vida cotidiana de la población. El crecimiento de los actos considerados delito, en el transcurso de la radicalización interna y externa del Tercer Reich, condicionó (desde 1939 y, especialmente, desde 1942) el crecimiento de los aspectos y "delitos" visibles de la "resistencia individual”.

Dentro del tipo de delitos relacionados con la resistencia individual podemos encontrar formas diversas: expresiones derrotistas, circulación de rumores, críticas a la dirección política, chistes e insultos a los dirigentes, expresiones pro-católicas, canciones prohibidas, opiniones favorables a los judíos, relaciones con prisioneros de guerra, no colaboración en las actividades del Partido, etc.

Las motivaciones que provocaban este tipo de comportamientos son tan variadas como el número de personas que estuvieron implicadas en estos casos: consideraciones humanitarias, compasión por los perseguidos, odio contra el régimen, desengaño por las promesas incumplidas, problemas provocados por la guerra, etc. Todo esto permite afirmar que la "resistencia individual" no es una resistencia elitista o concienciada, sino que se origina directamente a partir de las distintas reacciones ante los acontecimientos de la vida diaria, de aspectos cotidianos, con el día a día de la población. Se trata, por tanto, de una oposición “desde abajo" y, a menudo, relacionada y complementaria de otras formas de resistencia que, mayoritariamente, está formada por personas con una mayor conciencia política.

En este contexto, el humor, la sátira política, se convierten en una expresión cercana a la realidad cotidiana, manifestaciones de vivencias populares y la imagen que tenían del régimen. Es una expresión de desafío. Pero su verdadera importancia está en su persecución como actitud opositora, el hecho de que el régimen invirtiese una gran 
cantidad de recursos en la persecución de estas actitudes. La extensión de estas expresiones era una forma menor de articular un sentimiento de resistencia o inconformismo, porque servía como válvula de escape a las tensiones sociales creadas por la interacción con el régimen.

Es en un sistema de control de todas las expresiones posibles del pensamiento que aparece el florecimiento de la sátira y el sentido del humor político, que se nutre de las reservas e ingenio a las que el sistema totalitario niega su forma de expresión natural. Muchas de las opiniones "sediciosas" que se presentaban ante los tribunales estaban relacionadas con el humor anti-nazi, considerado como propaganda de oposición.

En esta situación el chiste político, el humor público, convertido en el flagelo de los defectos, el desenmascaramiento de la mentira propagandística y la burla de los políticos, el auténtico "humor de horca" florece especialmente cuando la libertad de expresión es reprimida. Todos los regímenes dictatoriales temen la sátira política porque aclara si la mentira se hace pasar por verdad, porque desenmascara su régimen, logra la solidaridad entre los reprimidos y perseguidos y fortalece el espíritu de la resistencia. Por temor a los lazos sociales que puede crear esa sátira, el gobernante toma medidas draconianas. Durante el dominio nacionalsocialista, la extensión del chiste político era castigada con la detención y, a causa de sus efectos desmoralizantes, con la muerte ${ }^{10}$.

El humor político tenía unas consecuencias directas en la sociedad: la sátira política o el derrotismo lograba neutralizar los esfuerzos del régimen para elevar la moral y el estado de ánimo de la población. Por ejemplo, el "saludo alemán” inspiró der deutsche Blick (la mirada alemana): quedarse quieto y volver furtivamente la cabeza, en ambos sentidos, en una rotación lo más amplia posible, antes de iniciar una conversación subversiva. En este sentido, la sátira política adoptaba dos objetivos principales. Por un lado, pretendía ridiculizar al sistema, burlándose de sus normativas, dirigentes e instituciones. Por otro lado, servía para evitar el propio respeto o miedo que inspiraba el régimen, mediante la ridiculización de aspectos cotidianos como la escasez de alimentos.

En la extensión del disentimiento tuvo una gran influencia el incremento de los precios, la congelación de los salarios, el racionamiento y otros problemas derivados de la situación de guerra, problemas que afectaron profundamente al estado de ánimo de la población, debido a que el régimen, centrado desde mediados de la década de 1930

${ }^{10}$ Véase también WÖHLER, Meike, Der politische Witz in der NS-Zeit am Beispiel ausgeruchter SD-Berichte und Gestapo-Akten, Wien, Peter Lang Verlag, 1997; BIEBER, Alain, Der politische Witz, München, Grin Verlag, 2001. 
en la "economía de guerra” y el conflicto bélico, transformó los aspectos más cotidianos de la vida de la población.

Un ejemplo de esta circunstancia fue la situación de la población católica, que también encontró sus propias formas de expresar su descontento con el acoso al que fue sometida la Iglesia. Por eso, muchas de las acusaciones por "expresiones enemigas del Estado" tenían un trasfondo religioso, sobre todo las relacionadas con la represión del culto y la enseñanza católica. «Los Días de María católicos han cambiado de nombre. Ahora se llaman: María-detención, María-denunciada, María-registro domiciliario» ${ }^{11}$.

La extensión de este fenómeno fue calificada, por el propio régimen, de "preocupante", como se expresaba en un informe del SD (Sicherheitsdienst, Servicio de Seguridad), en julio de 1943: «los que explican chistes perjudiciales para el Estado sobre la persona del Führer se han incrementado desde Stalingrado [...]. El sentimiento de que escuchar y explicar después chistes políticos es un golpe seguro contra los alemanes y nacionalsocialistas decentes y que es una simple imposibilidad se está perdiendo en amplios círculos de población y también entre una parte de los militantes del Partido» ${ }^{12}$.

Los temas relacionados con la extensión de la sátira política fueron muy diversos y se ampliaron con cada ámbito social o cada operación bélica que se producía.

- El humor referido a la escasez de alimentos: «A tres condenados a muerte por el Tribunal Popular se les pregunta sobre su última comida y dónde desean ser enterrados. El socialista pide un asado de cerdo y quiere yacer junto a Victor Adler. El social-cristiano desea un asado de pollo y quiere ser enterrado junto a Lueger. El tercero, un judío, desea plátanos. Se le dice que durante la guerra no pueden conseguirse. El judío: 'Puedo esperar'. Sólo debe decir dónde desearía ser enterrado. Entonces dice que junto a Hitler. Le gritan que si está loco. Hitler aún vive. 'Puedo esperar, se lo he dicho ya una vez antes'»13.

- La sátira referida a la figura del Führer: «De un ensayo escolar: los judíos querían destruir la cultura alemana y arruinar nuestra Patria totalmente. Pero nuestro Führer Adolf Hitler se les ha adelantado» ${ }^{14}$.

- Sobre la jerarquía del Partido Nacionalsocialista: «Las relaciones con la Santa Sede están interrumpidas. Hitler envía a su representante Hess, para mediar

\footnotetext{
${ }^{11}$ DANIMANN, Franz, Flüsterwitze und Spottgedichte unterm Hakenkreuz, Wien, Ephelant, 2001, p. 113.

12 Ibidem, p. 8.

13 Ibidem, p. 68.

14 Ibidem, p. 24.
} 
en esto. Hess no vuelve y envía un telegrama: 'he vuelto al seno de la Iglesia'. Hitler confía a Goebbels la misma misión. Éste telegrafía después de poco tiempo: 'he recuperado la fe de mi juventud, ingreso en un convento'. Entonces Hitler envía a su mejor pieza, Göring; después de dos días llega un telegrama: 'he cumplido la orden. Papa destituido. La tiara me sienta bien. Papa Hermann I'»15.

- Sobre el Partido y sus militantes: «Un auténtico alemán debe tener tres cualidades en el Tercer Reich. Debe ser honesto, inteligente y nacionalsocialista. Pero apenas encontramos estas tres cualidades juntas, un alemán tiene sólo dos. Es honesto e inteligente, pero entonces no es nacionalsocialista. Es inteligente y nacionalsocialista, pero entonces no es honesto. Es honesto y nacionalsocialista, pero entonces no es inteligente» ${ }^{16}$.

- Sobre el conflicto bélico: «¿Cuál es el país más hospitalario con los visitantes? Rusia. Nos han soportado dos años y ahora nos acompañan hasta casa»17.

- Sobre la represión y el terror desarrollado por el régimen: «Ya que en el extranjero se afirma que los nazis no tienen sentido del humor, el Ministro de Propaganda del Reich Joseph Goebbels ha instaurado un concurso para el mejor chiste político. Se han establecido los siguientes premios: primer premio: cinco años de prisión. Segundo premio: tres años en el campo de concentración de Dachau. Tercer premio: visita a los sótanos de la sede de la Gestapo, con el consiguiente interrogatorio ${ }^{18}$.

\section{El papel de la represión}

En sus esfuerzos por descubrir las formas de resistencia y oposición, muchos historiadores han perdido de vista frecuentemente el papel que jugó la colaboración y el consenso por parte de la población. El régimen no podría haber llevado a cabo durante mucho tiempo sus planteamientos políticos, sin tener una buena base de consenso, ya fuese forzado o pasivo, de un amplio estrato social.

Según el historiador B. Moore, uno de los prerrequisitos para que existan expresiones de descontento, de desobediencia, es la existencia de espacios sociales y políticos que permitan un nivel mínimo de movilización. Pero el consenso de la población tenía como efecto eliminar aquellos enclaves más o menos protegidos en que

\footnotetext{
15 Ibidem, p. 37.

${ }^{16}$ Ibidem, p. 96.

17 Ibidem, p. 128.

18 Ibidem, p. 96.
} 
los grupos de descontentos podían desarrollarse ${ }^{19}$. Por tanto, en la medida en que el régimen incrementaba los niveles de complicidad, se reducía el espacio de la resistencia.

La relación entre los delitos, sus autores y la represión sólo puede considerarse en el ámbito del marco de observación, control, persecución y terror del Nacionalsocialismo. Por ello se desarrolló un amplio sistema de vigilancia y control, que se hizo cargo de la supervisión del estado de ánimo general de la población, al mismo tiempo que también se hacía cargo de la observación de los enemigos concretos del régimen. A pesar de todos los llamamientos y de todos sus esfuerzos, las autoridades no consiguieron eliminar a los criticones, alarmistas y derrotistas.

El régimen nacionalsocialista consiguió aislar y castigar con dureza un tipo de conductas que para nosotros serían casi ridículas, desde el punto de vista de nuestra experiencia democrática. Pero la actitud del régimen nos ofrece una valiosa información adicional sobre los fracasos de su política integradora, aunque no podemos afirmar que esos esfuerzos fracasasen, porque la mayoría de los sectores sociales se mostraron permeables a una dinámica como la del Führerkult (el culto al Führer).

La dirección del régimen reconoció rápidamente la peligrosidad de estos delitos para la estabilidad de su sistema de dominio, e intentaba combatirlos por medio de la propaganda masiva y los llamamientos a la población para que se denunciase a los "delincuentes". Las actividades relacionadas con los actos de "resistencia individual" no hubieran sido conocidas por las autoridades sin la participación social: la mayoría de los procesos iniciados derivaban de informaciones de denunciantes o eran provocados por conflictos personales que una de las partes solucionaba de ese modo, y pocas de las denuncias tenían un trasfondo político claramente definido; se trataba de un recurso para "saldar cuentas" personales. Para la persecución de estos delitos fueron creados los Sondergerichte (Tribunales Especiales), que se extendieron por todo el Reich, aunque los casos más graves fueron dirigidos directamente al Volksgericht (Tribunal Popular), una de las herramientas más feroces de represión nazi.

Pero una de las herramientas más importantes del régimen fue la Geheime Staatspolizei (Gestapo, policía política), que empleó una gran cantidad de tiempo y esfuerzo contra estos delitos y esas formas de descontento popular, y que, para tener acceso a los "delincuentes", contó con la colaboración social, a través de la denuncia. A través de sus órganos de control social, el régimen intentó siempre que ese descontento,

19 MOORE, Bob, «Occupation, collaboration and resistance: some recent publications on the Netherlands during the Second World War», in European History Quarterly, 21, 1/1991, pp. 109-118. 
esas críticas, no se extendiesen al conjunto de la población. Gracias a las intervenciones del sistema represivo nazi, las actas de los tribunales y los documentos policiales se han convertido en una auténtica colección de humor, juegos de palabras y versos satíricos, que demuestran un gran sentimiento de agresión contra el régimen y lo que éste representaba.

Una de las principales formas de expresión del conflicto entre la población y el régimen fueron los "delitos verbales", basados en la Ley contra ataques maliciosos contra el Estado y el Partido y para la protección de los uniformes del Partido, de diciembre de 1934. Este texto, como solía ser habitual en la legislación nazi, era sumamente indefinido, de forma que podía ser empleada en casos muy diferentes: $S e$ podía tener 'suerte' y ser acusado sólo por 'malicia', pero también se podía tener 'mala pata' y, para un comportamiento o expresión similar, ser acusado de 'minar la fuerza de defensa'20.

Dentro de estas formas de desafío, el denominado "saludo alemán" era una muestra pública de apoyo al régimen, una forma de integración social, haciendo de su uso un elemento semi-obligatorio que se fue extendiendo al conjunto de la sociedad. A pesar de esto, en las zonas rurales o en los distritos obreros urbanos continuó utilizándose el saludo tradicional, que servía también como elemento diferenciador entre el régimen y la vida cotidiana de la población. Así, el saludo se convirtió en una nueva expresión de resistencia individual: a menudo encontramos informes policiales que nos señalan que el saludo era una forma de provocación. Para el régimen, la introducción de comportamientos como el saludo alemán estaba destinada a crear una cohesión interna que sirviese a su proyecto de homogeneización social, en un momento en que el saludo tradicional quedó relegado al pasado, para poder educar a los jóvenes en su papel de dominadores sin interferencias del "tradicionalismo" (catolicismo, obrerismo, etc.).

El rechazo al saludo se correspondía con un enfrentamiento a un hecho impuesto, convirtiéndose así en una actitud de ejercicio general de protesta individual. La población, especialmente los sectores obreros, establecieron propuestas alternativas a la introducción de estos comportamientos en sus ámbitos sociales. «Hitler viaja a Viena y un hombre lo saluda con un amistoso ‘buenos días’. ‘Cómo se atreve?’ le grita el Führer, 'desde que yo gobierno se saluda con 'Heil Hitler!'. iYa no hay buenos días, ni buenas tardes, ni buenas noches! ¿Entendido?»’21. Entre otras expresiones contra el régimen tuvo gran importancia la difamación contra el Führer, hasta que se creó una forma jurídica de delito, el Führerbeleidigung (insulto al Führer), considerado como

${ }^{20}$ FREI, Bob, Der Kleine Widerstand, cit, p. 8.

${ }^{21}$ DANIMANN, Franz, Flüsterwitze, cit., p. 18. 
una respuesta negativa al "culto al Führer" introducido por el régimen como elemento de integración. Una gran parte de la población veía en la figura de Hitler un símbolo nacional que, por lo general, se mantuvo exento de las críticas generalizadas que afectaban al sistema. Por eso, en la documentación no debemos limitarnos únicamente al insulto, sino también al ámbito, la indignación, la rabia entre la población, que no aparece reflejada en la documentación de las autoridades, y que convierte el insulto en una forma sustitutiva del ataque físico.

Estos insultos abarcaron un gran abanico de aspectos, pero mostraban a Hitler como un megalómano, idiota, criminal, timador, golfo, etc., aunque la principal preferencia eran los insultos obscenos o escatológicos. Los insultos sexuales se basaban en los rumores sobre las anormalidades sexuales de Hitler, que ocupó a menudo la imaginación popular. Otra variante era el uso de las propias teorías raciales nazis para ponerlas en contra de los líderes del Partido y del propio Hitler. Sin embargo, no fue Hitler el único dirigente que atrajo las críticas de la población: algunos historiadores distinguen claramente entre la popularidad de Hitler y la impopularidad del resto de dirigentes, especialmente después del comienzo de la guerra ${ }^{22}$. La teoría popular más extendida era que si algo podía recriminarse era porque lo había llevado a cabo alguno de los asistentes del Führer. Este "envilecimiento" de los dirigentes no puede considerarse equivalente al rechazo al Partido ni a la ideología nazi²3.

A pesar de todo, el número de casos relacionados con expresiones despectivas contra Hitler no debe engañarnos, ya que el Führer se mantuvo, casi hasta el final de la guerra, como un elemento de integración social. La imagen de Hitler se había construido sobre la base de su papel en la recuperación económica, política y social de Alemania, y sobre sus éxitos en la esfera internacional. Cualquier efecto que la imagen de Hitler hubiese tenido sobre la población se vio completamente trasformada a partir de los millones de carteles colocados en cualquier rincón del Reich. Además, la prensa y el cine ofrecían un flujo constante de imágenes cuidadosamente preparadas, que borraban cualquier mala impresión del pasado, creando la sensación de integración en una Volksgemeinschaft deseada por el Führer.

Otro elemento distorsionador eran las constantes colectas del Partido, criticadas con un fuerte componente público que afectaba directamente a la imagen del régimen. Especialmente odiada era la campaña de la Winterhilfswerk (Ayuda de Invierno), que

22 STOKES, Lawrence D. (ed.), Germans against Nazism. Nonconformity, opposition and resistance in the Third Reich, New York, Berg, 1990.

${ }^{23}$ KERSHAW, Ian, Der Hitler-Mythos. Volksmeinung und Propaganda im Dritten Reich, Stuttgart, Deutsche Verlag, 1986, pp. 96-104; KERSHAW, Ian, KOCHMANN, Klaus, Der HitlerMythos: Führerkult und Volksmeinung, München, Deutsche Verlags-Anstalt, 1999. 
concentraba la rabia de la población: los carteles eran arrancados, se hacían comentarios y pintadas sobre los "mendigos" (recolectores), se rechazaba la participación y se consideraban las contribuciones como dinero perdido, y se criticaba la propaganda del régimen: «Cartel de la Ayuda de Invierno, en el invierno de 19431944: "Nadie debería estar hambriento, nadie debería helarse". Un trabajador comenta con otro, “Ah, ¿̇eso tampoco deberíamos hacerlo?”»"24.

La sátira y la crítica contra el régimen se mostraron de forma muy importante en relación con el descontento y las críticas a la guerra, que se reflejaba en la oposición a la propaganda del régimen. Estas expresiones contra la guerra eran lo que los juristas nacionalsocialistas calificaron como Defaitismus (derrotismo) que, como delito, corrió paralelo al curso de la guerra y se expresó más extensamente a partir del comienzo de los reveses en el frente, especialmente de Stalingrado, una actitud ampliada en el conjunto de la sociedad. Incluso en la fase de éxitos militares iniciales, la hostilidad hacia la guerra se mantuvo cuando se hicieron sentir sus efectos sobre el nivel de vida de la población. Muchos fueron los aspectos relacionados con la guerra que provocaron el rechazo entre la población, pero uno de los más importantes fue el de los bombardeos aéreos y los daños que éstos provocaban en la sociedad alemana. «Un damnificado por un ataque aéreo, cuyo piso ha sido completamente destruido, se presenta en la oficina para regulación de los daños aéreos. En la antesala ve dos puertas: para damnificados graves, para damnificados leves. Ya que lo ha perdido todo, entra por la puerta de damnificados graves. Allí ve de nuevo dos puertas: para acomodados, para no acomodados. Ya que no tiene bienes, entra por la puerta de no acomodado. Nuevamente dos puertas: para camaradas de Partido, para no camaradas del Partido. Ya que no es camarada del Partido, abre la puerta para no camaradas del Partido y se encuentra de nuevo en la calle» 25 .

En casos especialmente graves de derrotismo se aplicaba la legislación de guerra, que establecía que los acusados podían ser condenados a muerte, por incitación a negarse a prestar el servicio militar o socavar la confianza de la población en la victoria alemana. La ordenanza regulaba los procedimientos de esos delitos ante los Sondergerichte (tribunales especiales), donde se buscaba una condena inmediata. Lo más sorprendente de esta legislación fue que, en la mayoría de los casos, la población no llegó a conocer la existencia de estas normativas.

Cuanto más cercano estaba el final de la guerra, más implacable fue la represión, más numerosas las condenas de muerte y más penas de prisión se dictaban. Pero, poco

24 DANIMANN, Franz, Flüsterwitze, cit., p. 16.

25 Ibidem, p. 123. 
a poco, tanto el humor como la sátira que circulaba entre la población comenzaron a hacer referencia directa a la situación que se crearía tras el final del conflicto y a las posibilidades de supervivencia de la población. «Un maestro pregunta a los alumnos qué lengua extranjera quieren aprender después de la guerra. Uno dice: "Mi padre nos hace aprender inglés, porque mi madre quiere emigrar después de la guerra”. Otro dice: "nosotros aprendemos español, porque queremos ir a Sudamérica”. El tercero dice: "nosotros aprendemos ruso, porque mi madre quiere quedarse aquí"»²6.

\section{Algunas conclusiones}

A lo largo de las páginas anteriores hemos visto una gran parte de los comportamientos y acciones que fueron considerados "delitos" entre 1933 y 1945. Hemos visto también una parte de los mecanismos que la sociedad utilizó para evitar y escapar del férreo control ejercido sobre la opinión pública y las expresiones de descontento. Finalmente, también hemos visto cómo la cotidianidad, el día a día, se veía influido por un gran número de cambios que tenían lugar en el ámbito político, social, económico o militar.

En muchas sentencias relacionadas con estas actividades se incluían consideraciones relacionadas con sus aspectos políticos, sobre todo en los ataques contra el Führer o al Partido. Se señalaba también cómo la actitud de los "delincuentes" afectaba a la "voluntad de lucha" de la población o minaba la "fuerza de defensa" de la misma. Pero en muchos casos no podemos evitar la impresión de que los fiscales y jueces no podían tratar estas pruebas incriminatorias sin sonreír. El humor satíricopolítico supone una fuente de información muy importante, porque nos proporciona declaraciones sobre las preocupaciones, necesidades y actitudes de la población, desde un punto de vista que, generalmente, queda marginado en los estudios históricos.

Desde el punto de vista de nuestra investigación, la "resistencia individual" marca una frontera entre la hegemonía y la integración del régimen nazi, y las zonas de oposición y resistencia entre sectores de la población. Así aparecieron Resistenzzonen que el régimen no siempre pudo eliminar, al contrario de lo que sucedía con la resistencia política organizada. Muchos autores consideran este comportamiento de inconformismo como factores secundarios frente a los grandes movimientos de resistencia organizada. Sin embargo, las nuevas corrientes de investigación, especialmente la historia social y la Alltagsgeschichte (la historia de la vida diaria) nos

26 DANIMANN, Franz, Flüsterwitze, cit., p. 145. 
deja ver que no es oportuno minimizar este fenómeno, ya lo denominemos "oposición individual" o "inconformismo con la vida diaria", porque aglutinó a un gran número de personas que ayudaron a crear y configurar una nueva identidad, gracias a su oposición al régimen nacionalsocialista.

Estamos hablando de un grupo relativamente representativo del conjunto de la población: ante los tribunales pasaron personas monárquicas, republicanas, comunistas, conservadoras, católicas, legitimistas, etc., acusadas de estos delitos. En realidad, es tan importante la forma en que la crítica se extendió entre la población como la incapacidad del régimen para asumirla. Lo que dificulta que podamos tener una medida real del comportamiento resistente no son sólo las fluctuaciones del descontento potencial provocado por el desarrollo de los acontecimientos, sino también los factores determinantes introducidos por el régimen y las normativas y actuaciones de éste en relación con la oposición. 


\section{* El autor}

Doctor en Historia Moderna y Contemporánea por la Universidad Autónoma de Barcelona. Su tesis doctoral, Nazismo y resistencia en Austria. Oposición, disentimiento, consenso y policía política. Viena (1938-1942), recibió excelente cum laude, con Premio Extraordinario de doctorado. Paralelamente ha publicado distintos artículos de investigación en revistas científicas como Historiar, Historia Social, Segle XX, etc. Se ocupa de temas relacionados con la historia del Tercer Reich y el Nacionalsocialismo, dedicándose especialmente al análisis del sistema de represión.

URL: < http://studistorici.com/progett/autori/\#DeToro >

\section{Per citare questo articolo:}

De TORO MUÑOZ, Francisco Miguel, «La sátira y el humor político durante el Tercer Reich. Los delitos contra la Volksgemeinschaftı, Diacronie. Studi di Storia Contemporanea: La satira fa storia. Eventi, pratiche, linguaggi, 29/10/2012,

URL:<http://www.studistorici.com/2012/10/29/de-toro_numero_11/ >

Diacronie Studi di Storia Contemporanea of www.diacronie.it

Risorsa digitale indipendente a carattere storiografico. Uscita trimestrale. redazione.diacronie@hotmail.it

Comitato di redazione: Marco Abram - Giampaolo Amodei - Jacopo Bassi - Luca Bufarale - Gianluca Canè - Alessandro Cattunar - Alice De Rensis - Barbara Galimberti - Deborah Paci - Fausto Pietrancosta - Matteo Tomasoni - Luca Zuccolo

Diritti: gli articoli di Diacronie. Studi di Storia Contemporanea sono pubblicati sotto licenza Creative Commons 2.5 Possono essere riprodotti a patto di non modificarne i contenuti e di non usarli per fini commerciali. La citazione di estratti è comunque sempre autorizzata, nei limiti previsti dalla legge. 